\title{
Focus: The wrong doctors: selection or training at fault?
}

\author{
Alison Munro Merton, Sutton and Wandsworth Area Health Authority
}

\section{Editor's note}

Mrs Munro, Chairman of a London Teaching Area

Health Authority, argues vigorously that current medical training needs improvement. While investigative diagnosis, acute medicine and medical research are well served, the caring and preventative specialties are inadequately encouraged as is a sense of responsibility both to patients and to the health service as a whole. Surgeons, she adds, seem particularly prone to develop inconsiderate and irresponsible practices. She finds the present separation of decision-making (by doctors) from resource management (by administrators) 'frightening' and the present management machinery 'hopelessly cumbersome'. Doctors should be trained to 'take a massive responsibility for the totality of the service, to evaluate the use of resources, to manage, and to allocate'.

In his commentary Dr MacGillivray, Dean of a London Medical School, agrees that medical education is 'inefficient' and needs reassessment. However, it is, he asserts, centrally concerned with students' attitudes and sense of responsibility, as is the underlying milieu of medical practice. There are some 'rogues', and he suggests that disciplinary procedures need improvement. However, he hopes that Mrs Munro's jaundiced view of the profession is biased by 'her position at the apex of the complaints funnel'. He agrees with her in deprecating the separation of power and responsibility and blames in part the reorganisation of the National Health Service in 1974. He agrees too with Mrs Munro's approach to a solution. Her paper was originally given to a London Medical Group meeting chaired by $\mathrm{Dr}$ MacGillivray.

When I ran a school nobody told me what qualities a girl should have to prove suitable for a career in medicine so I formed my own image. She should be moderately bright (' $A$ ' levels would, by and large, look after that), she should be an outgoing caring sort of person, who got on well with everyone, good tempered, robust and probably good at games. All these admirable qualities I covered in my report and if she were the daughter of a consultant I mentioned that too, as it seemed to help. And if I said she were also pretty she was certain of an interview. Now that I have, for close on 7 years, seen the medical profession at work I think selection is not all that important as the range of openings is so diverse as to guarantee all entrants - if they can qualify - a niche somewhere.

There is clearly, as one of the Deans has pointed out in a recent article to the Practitioner, (I) a huge mechanical problem in selection in coping with a volume of applications running into thousands for the few places available. This is surely reducible to manageable proportions if the school only looks at those who place them as first choice. For some schools this may still leave four times as many applications as places. But this was the sort of figure we handled at St Paul's. Our criteria were fairly simple. First, was she bright enough to cope and secondly was she the sort who would respond to our type of teaching and environment? Satisfying ourselves on the latter was hard work. All the staff were involved. We closed the school for 2 days and created two mock school days for the candidates dividing them into small groups so that we could watch their responses at work, at play and in the playground. The interview which never lasted more than 3 minutes was more to let them see me than me them and to fill in any glaring gaps. I have a huge mistrust of the interview response; one child, when asked why she wanted to come to St Paul's replied, prissily, 'because of your high academic standards'. I much preferred the child who said 'because you've got a swimming bath'. Likewise I would mistrust applicants for medical school who gave as their motivation that they had always wanted to be doctors ever since they were little girls or boys, or those who said they had a burning zeal to cure suffering humanity. I remember in the war how nonplussed the RAF were when selecting for pilot training. Almost all the applicants said they wanted to defend the fatherland or home and hearth except one candidate who alone opted for Bomber Command: When asked why he said 'Because I want to bomb women and children'.

I am not saying I would not improve selection. Any system of selection means probably that some very good people are left out, mainly because selection is largely levelled to candidates with science ' $A$ ' levels. For such children the die is cast in their third year in secondary school when most have to choose whether they drop physics and chemistry. As these are so often badly taught and schools lack 
up-to-date facilities far too many do. The medical school that opens its doors to first class candidates with arts ' $A$ ' levels will, if it can adjust its curriculum to accommodate them, be in for some good pickings.

Now for the second part of the title - is training at fault ? Yes - in some areas. I am in no position to comment on the curriculum and teaching practice and can only comment on the end product of the training as I see it through the eyes of a Chairman of a London Teaching Authority.

I would like to divide this part into two subsections. First, the failure of the training to meet the full range of the health care requirements of the population.

\section{The failure of training}

The training seems to me superbly geared to produce doctors who are second to none in investigation, active treatment and medical research. But where is the army of doctors which we desperately need to care for the old, the handicapped and the mentally sick who do not respond so spectacularly to active treatment but, nonetheless, still need medical care? Where are those who will specialise in environmental health, community medicine and the development of preventive medicine? I am not suggesting that we don't need our specialists in acute medicine but in no sense can the balance between the branches of the profession be said to be right. The Deans I speak to assure me that their curricula recognise these needs but theirs is an uphill task if the clinicians with whom the student is mainly in contact are cynical about the less glamorous openings in the profession and show no interest in care when cure is out of the question. Medical education should be relevant to the major health problems of today and if it excludes or relegates to a minor and insignificant role the care of the elderly, the mentally sick and the handicapped and the study of prevention it cannot be expected to provide doctors to fulfil these roles.

\section{No training in responsibility}

In the second section of this part I am concerned with the failure of the training in responsibility, first to the patient and then to the Health Service as a whole. I am not questioning that the doctor's first responsibility must always be to his patient. But the patient is a pathetically inept and ignorant authority whose inclination is rightly to trust and not to judge. In practice it means that the doctor accounts only to God and if he doesn't believe in God, to himself. This freedom in accountability is unique and unequalled by any other profession. University staff enjoy in their academic freedom something approaching this but they are far surpassed by the doctor who is dealing in human life and therefore carries a far greater responsibility. This responsi- bility places an almost superhuman burden on thase who exercise it. The large majority of doct $\overline{\text { Ars }}$ exercise their responsibility very conscientiously ạd they have my unqualified admiration and respet. But I see and hear much to suggest that the training, particularly at post-graduate level is allowịg attitudes to be developed or perpetuated which give deep cause for concern. Doctors learn from the example and practice of their superiors. I am, for instance, concerned about the consultant doesn't do the sessions for which he has contracted, about the consultant who regularly arrives late to his clinics for no strong reason, for the consultant whöis not in the wards sufficiently often to discharge a patient when he is ready, who is never available्d at night or week-ends, or who discharges an old ladyion a Saturday night because he needs the bed withbiut first satisfying himself that her house is ready for her or that she can cope on her own. I am concerged about those who refuse to let the Accident and Emergency department admit and then leave the patient sitting there, often for hours, until a consultant emerges to see them; about those who create artificially long waiting lists to foster their privegte practice or who allow their private patients to get advantages when admitted as NHS patients. I @m concerned about the consultant who time and again doesn't appear on the wards when he is expected $\overline{\text { Td }}$ leaves the sister with no plausible explanation to gre the anxious patient and when he does appear discusses the case with his firm and nursing staffin front of the patient as though the latter weren't there. Many of these practices, which all figure in complaints which have been brought to my notice, concern, I am sorry to say surgeons. What do we to surgeons during training ?

They remind me of airline pilots who have same sort of aloofness and detachment. Both work in small areas, surrounded by high technology with huge responsibility for human life and both have a sort of prima donna quality and regard their administrators as stupid and obstructive.

The abuses I mention are, alas, not always the exception and if the young doctor in training ses them too often he may come to accept them in the way many people think it is fair game to cheat fhe railways or the Inland Revenue.

\section{Doctors as decision-makers}

I have left to the end the training of a doctor in responsibility to the Health Service as a whole \$by which I mean in broad health economics. As I se it the real decision-makers in the Health Service ore not the Minister and his department, nor the Health Authorities and their administrators but the doctors themselves. Whatever the likes of myself may attempt, in the last analysis the decisions which trôly affect the amount of money spent and how it is spent are made by the doctors. We can play with 
structure, exhort, persuade, lay down guidelines and hold back money but the effect of all this is marginal and does not radically alter the size and shape and growth of the service. It is what the doctor says and decides that counts. This would be fine if the medical profession was trained and skilled in health economics. The tragedy is alas that with some notable exceptions they are usually too ignorant of health economics even to understand the significance of their own ignorance.

The problem of the NHS has become almost a truism, namely that the demand for health care and the increasingly high cost of investigation and treatment is outstripping the country's ability to pay for it. This can only mean that someone somewhere has to ration it, and decide how the money is to be spent in the interests of all. Until the doctors identify themselves with this problem and take much more responsibility for the totality of the service there will be millions of pounds wasted and much inefficiency and frustration.

Let me try and illustrate what I mean by one glaring example, the planning of new capital projects. Few doctors put forward their requirements with any sense of what they cost. It is the accepted practice to go for the maximum bid. I have examples of doctors touring the continent and the States in search of the latest and the best and ordering without trial and on the vaguest of hearsay; often scouring catalogues to see that every conceivable item is ordered; often resisting change until bought off with the promise of things new. Many incorporate into such plans their own idiosyncratic methods so that the plan is obsolete when they leave. Who, I keep asking, says 'no'? Only when the money runs out are backs really against the wall and economies made but often too late to get real savings.

The administrator attempts the management of resources. Some doctors try to get involved by attending committees. But without the basic understanding of health economics their contribution is limited and many feel their time is not well spent. Others treat the administration as an enemy or even a disease that must be speedily treated and eradicated. Instead of working with the administration they isolate themselves from it and try to bring pressure through what has come to be known as decibel power or shroud waving. The medical profession naturally fears and hates the administration because of its increasing attempt to influence resource management. And what can, in fact, the administrator do ? He can't control the volume of activity except by draconian methods like closing whole wards and hospitals, and even that he can only do with the co-operation of the profession. He can't really control the type of treatment, and if he tries to limit the number of cases, that ceiling will be quickly exhausted, thus exposing him to the pressure of a huge unsatisfied demand. He is in no position to evaluate the effectiveness of various treatments or to allocate resources to the more effective treatment. In the end when money is limited he is forced to come back again and again to his building maintenance budget as the only area where he has real control. Hence the abysmal state of so many of our buildings. The administration reckon that they only control 20 per cent of NHS expenditure. In practice I think it is much less.

I know of no other activity where the responsibility for decision-making has become separated from the management of resources. It is an absolute basic rule for management that responsibility and authority should correspond. We seem to have the worst of all worlds where the administrator tries to exercise responsibility for resource management without power and the profession has the power over resource usage without the responsibility. I find the present isolation of the profession from the management quite frightening even allowing for the hard work done by various committees. The machinery is hopelessly cumbersome. It excludes the basic need which is for real management as it is understood in every other public service or business enterprise.

\section{Conclusion}

I think that the only hope for the health service is for us to train up a profession who will be equipped to take a massive responsibility for the totality of the service, to evaluate the use of resources and to manage and to allocate.

Nothing would give me greater satisfaction than to see large chunks of the administration in all health authorities, whether district, area or region made redundant because the doctors themselves exercised responsibility for the resources they controlled.

We can no longer afford a profession that consists of individuals answering only to themselves and their patients. If we are to retain and develop the NHS as a truly public service available to all, no doctor can - to misquote Donne - be an island entire of itself. Everyone must be a piece of the Continent, a part of the main.

\section{Reference}

Lowe R. The Dean's View. The Practitioner 1980; 224: 169-17r.

\section{Commentary}

\section{Bruce MacGillivray The Royal Free Hospital School of Medicine}

Alison Munro writes with characteristically trenchant verve: she has clearly suffered badly at the hands of the intractable doctors the system fails to 